\title{
To describe an alien planet: An experience of landscape in The Voyage of the Beagle by Charles Darwin
}

\section{Justyna Schollenberger}

(Institute of Polish Culture, University of Warsaw)

\begin{abstract}
:
This text presents an attempt to reread Darwin's account of his journey on the Beagle. That account constitutes a report of meetings and confrontations with various "strangers": men, animals, as well as with different faces of otherness and exoticism, that culminate in a landscape so radically distinct from the European one, namely that of the South Pacific. This interpretation allows us to look at Darwin - the narrator - as more than just a naive traveler who observes and judges the world exclusively through the narrow perspective of British imperialism. The naturalist struggles with describing that which exceeds his previous experiences. The imperialistic perspective of landscape taken up in this text allows us to reflect on Darwin's perception of the landscape. The sights analyzed in the text are foremost treated as emanations of the powers of nature. At the same time, Darwin defines these sights in categories that are not scientific but aesthetic, finding them beautiful and sublime.
\end{abstract}

Keywords:

landscape, Darwin, landscape experience, imperialistic landscape, nature

In the last chapter of The Voyage of the Beagle, Charles Darwin writes about the Brazilian landscape as follows: "The land is one great wild, untidy, luxuriant hothouse, made by Nature for herself, but taken possession of by man, who has studded it with gay houses and formal gardens. How great would be the desire in every admirer of nature to behold, if such were possible, the scenery of another planet, yet to every person in Europe, it may be truly said, that at the distance of only a few degrees from his native soil, the glories of another world are opened to him" (Darwin 2008, 720). Hence, the naturalist does not come back to England from a journey "around the world," but rather from an extraterrestrial one. Nature itself turns out to be "extraterrestrial"; it surprises him with its richness and exoticism. 
Human activity, on the other hand, is much less interesting; it is ruled by an established pattern of ordering a given space-a wild area is transformed into a "formal garden."

In the passages under consideration, Darwin refers to areas that appear to be unspoiled by humans and too "wild" to ever be developed by man. The presented sights are treated as emanations of the powers of nature. At the same time, Darwin defines these sights in categories that are not scientific but aesthetic, finding them beautiful and sublime. Unlike his descriptions of other phenomena encountered in the course of his journey, the descriptions of tropical scenery, the tropical rain forests in particular, are very emphatic. Insofar as he looks upon landscapes organized by man from an imperialistic perspective, noticing what suits and what does not suit a certain British cultural model, he finds it challenging to describe these pristine views.

How can one intelligibly describe a different planet, when its essence lies precisely in this distinctness that is impossible to translate into anything familiar?

W. J. T. Mitchell, in his now classic article "Imperial Landscape" (2002), puts forward the thesis that the landscape constitutes a medium-namely, it serves primarily to convey cultural meanings and values. A landscape can be described as attractive, beautiful, wild, etc., only in a specific context; there is nothing in the landscape that makes it inherently so. In other words, what we describe as "natural" also results from a given cultural context. According to Mitchell, the landscape mediates between what is cultural and what is natural: "[It] is a natural scene mediated by culture. It is both a represented and presented space, both a signifier and a signified, both a frame and what a frame contains, both a real place and its simulacrum, both a package and the commodity inside the package" (Mitchell 2002, 5). Mitchell examines the relations between the landscape and imperialism; he shows, for example, how the British model of landscape was transferred to the territories conquered by the British Empire. In this sense the landscape becomes a tool of power and domination; it allows us to conceive of certain spaces (namely the South Pacific) as virginal, which can be described and ordered according to European standards. Mitchell writes: "The South Pacific provided, therefore, a kind of tabula rasa for the fantasies of European imperialism, a place where European landscape conventions could work themselves out virtually unimpeded by 'native' resistance, where the 'naturalness' of those conventions could find itself confirmed by a real place understood to be in a state of nature" $(2002,18)$.

Darwin's text follows this pattern of narration when describing Tahiti and New Zealand among others. According to Mitchell's work, he presents these lands as if they were incarnate "states of nature" while assessing if a given naturalness strives to a certain complex and primal harmony and beauty or, on the contrary, to a primal and primitive indolence. 
Gillian Beer, in her article "Writing Darwin's Islands" (1998), shows that The Voyage constitutes more than a testimony to a certain English, imperialistic perspective. In her interpretation, Darwin posits interesting shifts of scope between what is known (British) and what is unknown (alien). Beer focuses on his descriptions of the islands; she notices that in the second, revised, edition the naturalist pays more and more attention to describing the studied islands (among others, the Galapagos Archipelago). His conclusions regarding the geology of the islands are not limited exclusively to these unknown lands; after all, the basic Victorian narrative was grounded in England being an island. Beer argues against the thesis that can be found in the introduction to the abridged edition of The Voyage, written by Janet Browne and Michael Neve, who identify the cultural and political background of Darwin's work insofar as he observed the world from a very specific British perspective. Beer, while not contradicting the generally constructed thesis that Darwin presents a culturally determined attitude, stresses the continuous dynamic of his position. She asserts that, "instead, he more and more looked back with exotic and awakened eyes on the taken-for-granted England from which he set out" $(1998,130)$. England loses its status as the mainland from where one sets off to conquer the world and where one then safely returns to. It becomes, instead, just one more area to be examined. Thus, Darwin's perspective came to be marked in a sense, one could say "infected," by the radical otherness with which he was confronted. Consequently, sensitive to the unfamiliarity of the scenery that surrounds man, he began to notice a spatial alienation of human beings, an alienation that constitutes a condition of the familiar order brought by culture.

Darwin explains and describes a world of various life forms by comparing the known and the unknown. Rather than looking only at one fraction of reality, he immediately puts it into a network of relations with other phenomena. As Beer writes, "that capacity imaginatively [sic] to enjoy difference proves to be Darwin's central intellectual gift" $(1998,130)$. She goes on to suggest that this is the ability that allowed him to formulate his thesis on evolution and, one might add, to implement his travel experience in his scientific work. She endeavors to demonstrate the uniqueness of Darwin's writing and attitude, which is of course conditioned by cultural and social context without, however, being completely determined by the two. Darwin is able to abandon his "English" point of view and look at England from a foreigner's perspective; what is more, he can even study himself, just as he studies all the other objects of his observations. When confronted with an alien landscape, Darwin becomes "himself as another" (Ricoeur 1992).

The present article is an analysis of the report of landscape experience in Darwin's The Voyage of the Beagle. The book constitutes a narrative report of the journey, in which Darwin took part as a naturalist employed on the HMS Beagle from 1833 to 1836 , and which he himself considered to be the key event for his scientific discovery. It is not an exclusively scientific report; it is addressed to a wider audience as it 
falls into the category of travel and life science literature. It can be read as a certain anthropological overview-records of meetings and confrontations with different "strangers": people, animals, as well as various faces of otherness and exoticismthat emerge in this landscape which is so radically distinct from the European one. This interpretation allows us to look at Darwin-the narrator-as more than just a naive traveler who observes and judges the world exclusively through the narrow perspective of British imperialism. The naturalist struggles with describing that which exceeds his previous experiences. However, he is usually saved by the imperialistic narration that offers a convenient model for assessing the natives by comparing them to a certain British norm of being civilized. He may also turn to the discourse natural science and focus on an appropriate explanation of peculiar, at first glance, phenomena or on an appropriate classification of encountered exotic animals. Nevertheless, the problem of adequately describing a reality so radically exceeding everything that is known constantly resurfaces directly and indirectly in his prose. When experiencing an unknown space, he is confronted with the issue of otherness which lies in our gaze and language, which on the one hand should express it, and on the other hand, by representing it, also takes it over and domesticates it.

\section{Faces of otherness}

It seems that there are two manifestations of otherness that prove particularly defiant. The first is the otherness of the native inhabitants of Tierra del Fuego, whom Darwin calls savages, and the second is the landscape, which evokes a feeling of sublimity. At first glance, these two types of otherness, human and natural, demand different methods of interpretation and description; they put before Darwin the task of adequately reporting an experience that escapes all known categorization. The experience of the landscape's sublimity and the shock of the wild cannot be adequately described. The narration can only point to certain phenomena, while the sense of the experience remains beyond the text.

In the last chapter of The Voyage, Darwin recaps his journey; first of all, he accentuates his own discoveries. Secondly, he provides the reader with a brief review of the advantages and disadvantages of such long journeys. After emphasizing all the inconveniences of sea expeditions (that are particularly unpleasant for those who suffer from seasickness, which, according to the author's warning based on personal experience, is incurable), soothed solely by the vision of a long-awaited return to his beloved homeland, Darwin finally proceeds to why it is actually worth submitting oneself to this kind of suffering.

He lists the aesthetic pleasures related to admiring the landscapes and the sights so unlike those of Europe, as well as the opportunity to see with one's own eyes 
a most astonishing sight "the first sight in his native haunt of a barbarian-of man in his lowest and most savage state" (Darwin 2008, 730).

The savages, whose sight struck Darwin so, are borderline subjects. Their appearance, behavior, and customs are extremely uncivilized; they do not show any traces of the seemingly "natural" domination of man over the natural world. The Darwinian narration breaks down in the chapter about Tierra del Fuego, where he abandons the calm and paternalistic tone used to describe the population of South America in favor of a voice full of astonishment, horror, disgust, and confusion. The naturalist writes explicitly that the inhabitants of Tierra del Fuego are "our" ("we" refers here to Europeans) brothers, our forefathers even, since it is likely that the ancestors of "civilized" man looked and behaved in this way. This rational conclusion, while being in accordance with the theory of natural selection being formulated, does not erase the shock caused by his encounter with these savages. It is real and, at the same time, almost impossible to accept. The savages cannot be classified as animals; they are people without a doubt, nevertheless they do not behave the way men should. They escape the "anthropological machine," demanding a place outside the categories of "man" and "animal." They function similarly to the primitive "Homo alalus," distinguished by Giorgio Agamben, that, in $19^{\text {th }}$ century discourse, acted as a necessary link between the animal and the human, mediating between areas of that which is human and non-human (Agamben 2004, 35). The savages of Tierra del Fuego are on the lowest level of human development. They lack animal instinct and cunning, as well as the culture-bound ability to bend the unfriendly natural world to their own will. Cannon Schmitt even puts forward the thesis that, within Darwinian theory, which consequently moves and blurs the border between what is human and what is animal, the inhabitants of Tierra del Fuego were the last "real" men that in fact exceeded the natural order. As Schmitt writes, "necessarily existing at a point on that continuum, Fuegians are nonetheless also exiled from it. Neither human nor 'animal', too familiar to be ignored but too alien to be acknowledged kin ..., they stand alone" (Schmitt 2009, 56).

The inhabitants of Tierra del Fuego belong in the areas between culture and nature; they are humans and yet they do not resemble them. It is unclear what language to use to describe them. Darwin oscillates between a personal report of violent shock and a rational, evolutional discourse that perceives them as surviving forms of man at a very early stage of development. Nature, which allows for the meeting of representatives of the same species at such radically different stages of development, as Darwin sees it, seems to reveal its contrariness: "I do not believe it is possible to describe or paint the difference between savage and civilized man" (Darwin 2008, 730). 


\section{Sublimity: between experience and representation}

For Darwin, the landscape likewise resists description even though it evokes completely different feelings - namely, those of intense pleasure and sublimity. The landscape is where the mysterious power of nature manifests itself. In his words, "among the scenes which are deeply impressed on my mind, none exceed in sublimity the primeval forests undefaced by the hand of man; whether those of Brazil, where the powers of Life are predominant, or those of Tierra del Fuego, where Death and Decay prevail. Both are temples filled with the varied productions of the God of Nature: - no one can stand in these solitudes unmoved, and not feel that there is more in man than the mere breath of his body" (Darwin 2008, 729). Darwin keeps emphasizing the feeling of sublimity and how moved he was in places that seem untouched. Sublimity can only be evoked by that which is entirely wild and natural. The question we are left with being who exactly Darwin considers to be the people whose presence meaningfully impacts natural areas. In the last chapter, he states that one of the most emotional moments that awaits the European traveler is the realization that he is the first civilized man to be there: "I do not doubt that every traveler must remember the glowing sense of happiness which he experienced, when he first breathed in a foreign clime, where the civilized man had seldom or never trod" (Darwin 2008, 731).

What is characteristic of his descriptions of exotic sublimity is their being compared to a sublimity comprehensible to a European. The rain forest is compared to "the theatre or the opera," and while referring to his impressions of the expedition to the Cordillera, Darwin writes as follows: "When we reached the crest and looked backwards, a glorious view was presented. The atmosphere resplendently clear; the sky an intense blue; the profound valleys; the wild broken forms; the heaps of ruins, piled up during the lapse of ages; the bright-coloured rocks, contrasted with the quiet mountains of snow; all these together produced a scene no one could have imagined. Neither plant nor bird, excepting a few condors wheeling around the higher pinnacles, distracted my attention from the inanimate mass. I felt glad that I was alone: it was like watching a thunderstorm, or hearing in full orchestra a chorus of the Messiah» (Darwin 2008, 467).

Darwin was familiar with the aesthetic theory of Edmund Burke and his A Philosophical Enquiry into the Origin of Our Ideas of the Sublime and Beautiful (1824). Thus, his descriptions of sublime landscapes sound at times like philosophy homework done well. The naturalist knows what to look at and what should impress him. We ought to recall that Burke lists astonishment as a basic emotion rising from confrontation with "the great and sublime in nature" (Burke 1824, 97). Astonishment suspends our mental faculties as we become literally stunned by a given sublime object or sight: "The mind is so entirely filled with its object, that it cannot entertain any other, nor by consequence reasons on the object which 
employs it" (Burke 1824, 97-98). Darwin describes sublimity as an experience that allows us to discover the limits of our imagination; we are confronted by something that we would not be able to picture in our minds on our own. Hence, Darwin describes the Patagonian plains as sublime; even though they are barren, uninhabited, and infertile, they provide a complete freedom of imagination. Darwin writes: «I can scarcely analyze these feelings: but it must be partly owing to the free scope given to the imagination» (Darwin 2008, 729). That freedom of imagination is provoked by the vastness of the plains, which "are boundless, for they are scarcely passable, and hence unknown: they bear the stamp of having lasted, as they are now, for ages, and there appears no limit to their duration through future time» (Darwin 2008, 729-30).

It is worth stressing this anthropological aspect of perceivable infinity. The plains are not in fact infinite; they only seem to be so because grasping them lies beyond the physical and cognitive abilities of man. The naturalist notices what meanings are assigned to particular objects, phenomena, etc., within the scope of certain perspectives. Continuous references to the European point of view should justly be interpreted as a sign of the imperialistic discourse so deeply rooted in Darwin's narration. However, they could also be interpreted as a likely unintentional expression of anthropological honesty. Darwin reveals his own perspective as he writes about the world seen and understood through his experiences. In The Voyage, Darwin reveals, often incidentally, a fundamental problem related to the later formulated theory of evolution. General natural laws are impersonal, purposeless; man is but one of many animal species, he is not the main focus of nature. And these laws can only be described in a language that is anthropocentric in its essence; a language that anthropomorphizes what is non-human. In her book, Darwin's Plots (2009), Beer investigates the consequences of the literary style adopted by Darwin in On the Origin of Species-a work that is accessible to ordinary readers as opposed to being esoteric. Beer writes as follows: "He did not invent laws. He described them. Indeed, it was essential to his project that it should be accepted not as invention, but description. His work is, therefore, conditional upon the means of description: that is upon language" $(2009,46)$. Darwin will struggle with the anthropocentrism of language and its orientation towards indicating action and the object of that action. In The Voyage, the issues related to the coincidental necessity and incompatibility of the language used to describe and understand reality in a "natural" way are evoked by experiences, situations, and observations.

Two attitudes blend in his descriptions of the landscapes: one a subtly naive astonishment drawn out of the ineffable nature of aesthetic experience and the other a steadfast determination to overcome that ineffability and to succeed in describing and explaining it. Darwin writes from the perspectives of both writer and reader. As a reader of travel reports, he is able to assess the quality of the description of, for example, rain forests. As a writer, he paints for these amazing, exotic pictures 
just to soberly add, moments later, that they fail to express the true richness of nature.

Darwin singled out Personal Narrative by Alexander von Humboldt as the fullest description of South America. Indeed, he sets off on his journey as a literate man who knows what to expect; he has envisioned the unknown lands beforehand. He is also aware that his preconceptions and acquired knowledge may influence his perception of the terrain. The fact that the sight of rain forests exceeded all of his expectations constitutes the best proof for their actual magnificence, which cannot be matched by anything European. Darwin writes: "As the force of impressions generally depends on preconceived ideas, I may add, that mine were taken from the vivid descriptions in the Personal Narrative of Humboldt, which far exceed in merit anything else which I have read. Yet with these high-wrought ideas, my feelings were far from partaking of a tinge of disappointment on my first and final landing on the shores of Brazil" (2008, 729). Darwin, while wanting to testify to the magnificence of the Brazilian landscape, curiously confesses his faith in text, literature, and in the power of imagination from which one could almost expect a complete representation of the natural world.

Alexis Harley, in her book Autobiologies (2015), notes that the question of the authenticity of the experience of sublimity is justified-did Darwin really feel it or was he just aware that he should feel it? How is one supposed to separate a particular cultural background, instilled by education and literature, from pure experience, which emanates from both external, scientific nature and human, emotional nature? Harley distinguishes two key authors for the scientific approach adopted by Darwin during his expedition, namely John Herschel and Humboldt, who was mentioned earlier. During his studies at Cambridge, Darwin read Preliminary Discourse on the Study of Natural Philosophy where Herschel assumes personal experience free of all "superstition" to be the only source of cognition. Furthermore, the scientist's approach is to be free of any subjectivity. Humboldt, on the other hand, uses an antirational and romantic language that anthropomorphizes the non-human world and, additionally, strongly emphasizes a subjective perspective. In this interpretation, Darwin would be torn between two different approaches to the status of personal experiences in scientific discourse. Harley notices that the use of the category of the sublime throughout the diary implies distance to lived experience; "Darwin does not just observe; he observes himself observing, and this evident self-awareness makes trouble for the seeming authenticity of his antirational rhetorical communing with nature" (2015, 57-58). Harley admits later that there is no serious evidence that discredits the authenticity of Darwin's experience of sublimity. What is interesting is that Darwin's text contains the very questions that it provokes. He also wonders to what extent previous readings can contaminate or even completely obstruct empirical reality. At the same time, he writes that our capacity to grasp the richness of alien nature depends upon prior knowledge. 


\section{To know and to see}

Darwin does not focus solely on experiencing the landscape aesthetically. In his interpretation, aesthetic sensitivity blends with the scientific. The naturalist writes that he sees more than a novice, hence he is able to appreciate more fully the beauty and splendor of nature. What is more, anyone that wishes to go on a journey to foreign lands and really take advantage of the opportunity should possess scientific knowledge.

Admiring landscapes in the course of a journey differs from simply admiring beauty, as the former is based on pleasure coming from the possibility of comparing different views. This is where the scientist has an unmatched advantage over a regular traveler. Thus, only one who knows the components of a landscape, who knows what he is looking at, can really appreciate its beauty: "I am strongly induced to believe that as in music, the person who understands every note will, if he also possesses a proper taste, more thoroughly enjoy the whole, so he who examines each part of a fine view, may also thoroughly comprehend the full and combined effect" (Darwin 2008, 728). He further stresses that when setting off on a journey one should have some understanding of botany, for it is the flora that gives us something to look at to begin with, "for in all views plants form the chief embellishment" (Darwin 2008, 728). Being in contact with nature is like being in contact with art; it can be thoughtless, but true beauty will reveal itself only to the expert. These claims are worth comparing to a difficult to interpret confession from Darwin's posthumous Autobiography (2009).

Therein, he reveals that he suffered from a decline (he describes it as interesting and deplorable) in his higher aesthetic feelings. He writes that up until turning thirty he would take enormous pleasure in reading poetry (during his journey on the Beagle, he would not part with Milton's Paradise Lost), Shakespeare's plays, and above all in music. However, that changed; "but now for many years I cannot endure to read a line of poetry: I have tried lately to read Shakespeare, and found it so intolerably dull that it nauseated me. I have also almost lost my taste for pictures or music. Music generally sets me thinking too energetically on what I have been at work on, instead of giving me pleasure. I retain some taste for fine scenery, but it does not cause me the exquisite delight which it formerly did" (Darwin 2009, 142-43). As a passionate naturalist he was, however, particularly sensitive to the beauty of nature: "In connection with pleasure from poetry, I may add that in 1822 a vivid delight in scenery was first awakened in my mind, during a riding tour on the borders of Wales, and this has lasted longer than any other aesthetic pleasure" (Darwin 2009, 17).

At the time, he only took pleasure in literature related in some way to factsnamely, novels of manners (which have to have a happy ending), biographies, and travel reports. Darwin writes further: "My mind seems to have become a kind 
of machine for grinding general laws out of large collections of facts, but why this should have caused the atrophy of that part of the brain alone, on which the higher tastes depend, I cannot conceive" (Darwin 2009, 144). This confession is shocking in its directness. According to Browne, the author of Darwin's monumental biography, his children reacted strongly to this confession and attested to his undiminished interest in beautiful views, music, and poetry. The researcher notes that this philistine attitude was not uncommon among British upper classes; hence, their contrary testimony could not be a question of fear of public stigma. Darwin, so sensitive to even the smallest elements of the living world, simply could not play a fool in the field of aesthetics. Browne writes that "it was as if Darwin was denying his sensitivity to nature, almost turning his back on his special gifts $(2002,645)$. It is worth noting that Darwin, nauseated by Shakespeare and bored by music, dedicated himself to detailed research of the life of earthworms, testing, among other things, their sensitivity to piano and harpsichord. We should also note that he observed himself as if he were a specimen, at the same time grieving the loss of his aesthetic sensitivity and curiously investigating the reasons behind it. How does one think about art after becoming indifferent to it? In The Voyage, Darwin writes about the inevitable ephemerality of experience. In a beautiful paragraph, he describes his last stroll through the Brazilian rain forest, during which he wonders how to convey their beauty and whether he would retain their actual picture in his memory: "In my last walk I stopped again and again to gaze on these beauties, and endeavoured to fix in my mind for ever, an impression which at the time I knew sooner or later must fail. ... Yet they will leave, like a tale heard in childhood, a picture full of indistinct, but most beautiful figures (Darwin 2008, 720). Darwin, while writing the book, tries to capture that moment when we are still aware of those thoughts and experiences that will soon be forgotten. He writes about his lost aesthetic sensitivity in a similar manner-he knows what he is no longer able to experience. Experience of an exotic landscape, impossible to simply convey either in poetic or scientific description, points to a space that cannot be grasped by fact-oriented cognition. Knowledge allows us to see, and by seeing a certain dimension is revealed, which can be embraced and overtaken by knowledge. When perceiving sublimity, knowledge goes blind. But could this "blindness" become an object of knowledge once again?

\section{References:}

Agamben, Giorgio. 2004. The Open: Man and Animal. Translated by Kevin Attell. Stanford: Stanford University Press.

Beer, Gillian. 2009. Darwin's Plots: Evolutionary Narrative in Darwin, George Elliot and Nineteenth-Century Fiction. New York: Cambridge University Press. 
Beer, Gillian. 1998. "Writing Darwin's Islands: England and the Insular Condition." In Inscribing Science: Scientific Texts and the Materiality of Communication, edited by Timothy Lenoir, 118-39. Stanford: Stanford University Press.

Browne, Janet. 2002. Charles Darwin: The Power of Place. New York: Princeton University Press. Epub Edition.

Burke, Edmund. 1824. A philosophical enquiry into the Origin of Our Ideas of the Sublime and Beautiful. London: A. Robertson \& Co.

Darwin, Charles. 2009. The Autobiography of Charles Darwin 1809-1882. Edited by Nora Barlow. London: Routledge.

Darwin, Charles. 2008. The Voyage of the Beagle. Cambridge: Cambridge University Press.

Harley, Alexis. 2015. Autobiologies: Charles Darwin and the Natural History of the Self. Maryland: Bucknell University Press.

Mitchell, William J.T. 2002. "Imperial Landscape." In Landscape and Power, edited by William J.T. Mitchell, 5-34. Chicago: The University of Chicago Press.

Ricoeur Paul. 1992. Oneself as Another. Translated by Kathleen Blamey. Chicago: University of Chicago Press.

Schmitt Cannon. 2009. Darwin and the Memory of the Human: Evolution, Savages and South America. Cambridge: Cambridge University Press. 